Military Technical College

Kobry Elkobbah, Cairo, Egypt

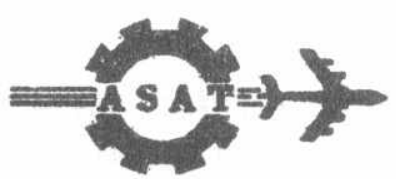

$8^{\text {th }}$ International Conference on Aerospace Sciences \& Aviation Technology

\title{
FLOW ADSORPTION MICROCALORIMERTY FOR DETERMINATION OF THE HEATS OF ADSORPTION AND DESORPTION ONTO VARIOUS MICROPOROUS CARBONS
}

\author{
A. Elbaz Elsaiid
}

\begin{abstract}
Toxic vapors may be removed from passing air streams with an activated carbon bed. The heat evolved during the removal process can affect the removal rates of the toxic vapors with the carbon bed. Flow microcalorimetry (FMC), in which the heat generated by adsorption of molecules from a gas or liquid flow stream is monitored and measured, can provide a wealth of information on the heat evolved and the adsorptive properties of activated carbon adsorbents. Heats of adsorption and desorption for each of toluene, trichloroethylene, and carbon tetrachloride from a nitrogen carrier gas stream on Ambersorb 572, a microporous activated carbon, have been evaluated and compared using FMC. In addition to Ambersorb 572, the heats of adsorption of toluene on Ambersorb 563, Maxorb AW20, Maxorb AW30, and West VacoA1100 activated carbons have been also determined by FMC and compared. The integral molar heat of adsorption of toluene on Maxorb AW20, a high surface area microporous activated carbon, as an example, was evaluated by two ways. a) Combining the FMC thermal results and the adsorption amount of toluene simultaneously determined with a photoionization down stream detector. b) Combining the FMC thermal results and the adsorption amount of toluene concluded from the equilibrium adsorption isotherm, determined gravimetrically using a microbalance, of toluene on Maxorb AW20. The molar heats determined by the two methods were in a qualitative agreement with each other.
\end{abstract}

\section{KEY WORDS}

Activated carbon, Adsorption, Heat of adsorption, Adsorption properties, and Microcalorimery,

\footnotetext{
"Associate professor, Dpt. of Chemical Engineering, Military Technical College, Cairo, Egypt.
} 


\section{INTRODUCTION}

Most toxic vapors are removed from passing air streams with an activated carbon bed through physical adsorption and chemical reaction. A significant amount of heat is evolved due to heats of adsorption and reaction during the removal of the toxic vapors with the carbon bed. The heats of adsorption and reaction increase the temperature of the carbon bed, which consequently affect the vapor-liquid isotherms and the removal rates of the toxic vapors for the carbon bed. Heats of adsorption and reaction are very important variables in the formulation of a material and energy balance for the nonisothermal carbon bed to develop a design model of the carbon bed.

The heat of adsorption of an adsorbate on a solid adsorbent and its variation with coverage will provide some information on the characteristics of both the surfaces of the solid adsorbent and the adsorbate. Heats of adsorption of a nonpolar adsorbate on an energetically homogeneous surface are generally almost independent of loading of the adsorbate and increase as the saturation limit is approached. Heats of adsorption of an adsorbate on an energetically heterogeneous adsorbent depend on the size of adsorbate molecule.

The heats of adsorption indicate the strength of the bonding between adsorbate and adsorbent surface. Physical adsorption from the gas phase is invariably exothermic. The driving forces of physical adsorption include both van der Waals force (dispersion- repulsion) and electrostatic interactions comprising polarization, dipole, and quadrupole interaction [1]. The heat of physical adsorption is higher than the value of the heat of liquefaction at low coverage. The heat of physical adsorption approaches the heat of liquefaction of the adsorbate, as the coverage of gas adsorbed on solid surface increases [2].

Activated carbons are disordered, microporous forms of carbon, with very high porosity and surface area. They can be prepared from a large number of raw materials [3-9]. High-surface area active carbon was developed by the AMOCO Corporation $[10,11]$. Since it has a large surface area and an excellent adsorption capacity, various applications were foreseen.

Flow microcalorimetry (FMC) has emerged in recent years as a simple, effective technique for characterizing solid, high surface area adsorbents in both liquid and vapor environments $[12,13]$. In general, a wide variety of applications have been explored [14]. The present paper describes an investigation on the adsorption of three adsorbates, namely: toluene, trichloroethylene, and carbon tetrachloride, from a nitrogen carrier gas strean on Ambersorb 572, a microporous activated carbon, and the determination of the accompanied heats of adsorption and desorption for each of them using FMC. In addition, the heats of adsorption of toluene on five adsorbents of 
microporous activated carbons have been also determined by FMC and compared. One adsorbent, Maxorb AW20, a high surface area microporous activated carbon, was selected and the integral molar heat of adsorption of toluene on it was determined.

\section{EXPERIMENTAL}

\section{Materials}

The adsorbents used in the study were five microporous activated carbons. Technical Data of these carbons were provided by the supplying companies and are given in Table 1. The adsorbates used were Fisher Scientific ACS certified grade toluene, trichloroethylene, and carbon tetrachloride.

Table 1. Technical data of used carbons.

\begin{tabular}{|l|l|c|c|c|c|}
\hline Carbon & \multicolumn{1}{|c|}{ Manufacturer } & Surface area & \multicolumn{3}{|c|}{ Porosity $(\mathrm{ml} / \mathrm{g})$} \\
\cline { 5 - 6 } & & $\left(\mathrm{m}^{2} / \mathrm{g}\right)$ & Micro & meso & total \\
\hline Ambersorb 572 & Rohm \& Haas Company & 1100 & 0.41 & 0.19 & 1.04 \\
\hline Ambersorb 563 & Rohm \& Haas Company & 550 & 0.23 & 0.14 & 0.67 \\
\hline Maxsorb AW20 & Kansal Coke \& Chem. Comp., L.t. & 2330 & 0.48 & 0.52 & 1.16 \\
\hline Maxsorb AW30 & Kansai Coke \& Chem. Comp., Ltd. & 3030 & 0.13 & 1.13 & 1.57 \\
\hline WV-A1100 & Westvaco Chemicals & 1650 & 0.31 & 0.70 & 1.20 \\
\hline
\end{tabular}

\section{Flow Microcalorimetry}

Flow Microcalorimeter (Microscal, Ltd. London, United Kingdom), Model 3Vi was selected for the present work. The technique gives a complete picture of thermal effects and mass transfer in a single experiment. The instrument which has been described previously $[12,13]$ is designed to measure small enthalpy changes, which occur during adsorption and desorption of predetermined molecular species carried in a fluid stream. The FMC operates isothermally and can link the test cell effluent to an appropriate Downstream Detector (DSD) so concentration changes can be monitored.

In the present study, the Microcalorimeter was placed in a constant temperature chamber that was controlled with a World Precision Instruments Air-Therm Heater Controller to $\pm 0.1^{\circ} \mathrm{C}$. Dry nitrogen gas was split into three streams. The flow rate of each stream was controlled by a mass flow meter. A Bronkhorst F201C - FD Mass Flow Meter / Controller supplied one pure nitrogen stream at a specified flow rate. This stream was employed to outgas the fresh sample and desorb the used adsorbate from the sample bed in the 
test cell. A second nitrogen stream, controlled by a Bronkhorst. F200C-FD Mass Flow Controller, was used to generate the vapor of the adsorbatie by flowing through a vapor generator containing that adsorbate. The vapor generator consisted of two bubblers in series to ensure saturation of the ritrogen stream with the adsorbate. The bubblers were placed in the bath of a Poly Science Digital Temperature Controller at temperature in the range 273$2.93 \mathrm{~K}$. The third stream, a pure nitrogen stream was supplied by a MKS Type $1259 \mathrm{C}$ Mass Flow Controller, joined with the second stream after the vapor generator and served to dilute the second stream to the desired concentration.

The experimental conditions are given in Table 2. The probe concentration was determined, assuming ideal gas behavior, from the saturated vapor pressure of the adsorbate at the generator temperature, the carbon bed temperature in the Microcalorimeter cell, the flow rate of the nitrogen stream that was saturated with the adsorbate, and the flow rate of the pure nitrogen diluting stream.

Table 2. Experimental conditions during runs.

\begin{tabular}{|c|c|c|c|c|c|c|}
\hline \multicolumn{2}{|r|}{ Adsorbent } & Adsorbate & $\begin{array}{l}\text { Mass flow } \\
\text { controller } \\
\text { flow }\end{array}$ & $\begin{array}{c}\text { Probe } \\
\text { concentration } \\
\text { (mg/l) }\end{array}$ & $\begin{array}{l}\text { Generator } \\
\text { temperature } \\
\text { (K) }\end{array}$ & $\begin{array}{l}\text { Carbon bed } \\
\text { Temperatture } \\
\text { (K) }\end{array}$ \\
\hline A & $\begin{array}{l}\text { Ambersorb } 572 \\
\text { Ambersorb } 572 \\
\text { Ambersorb } 57\end{array}$ & $\begin{array}{l}\mathrm{C}_{6} \mathrm{H}_{5} \mathrm{CH}_{3} \\
\mathrm{C}_{2} \mathrm{HCl}_{3} \\
\mathrm{CCl}_{4}\end{array}$ & 5.0 & $\begin{array}{l}62.0 \\
170 \\
95.6 \\
\end{array}$ & 273 & 313 \\
\hline B & All carbons & $\mathrm{C}_{6} \mathrm{H}_{5} \mathrm{CH}_{3}$ & 6.6 & 82.9 & 288 & 343 \\
\hline
\end{tabular}

Cleaning the sample chamber and loading it with a fresh adsorbent sample of a given weight $(25-100 \mathrm{mg})$ started each run. Adjusting various experinental conditions such as mass flow rates of different streams, temperature of the sample chamber, temperature of the generator bath, etc. followed that. Fresh samples of carbon were outgassed in the pure nitrogen stream for a specified period. A computer controlled 4 - way valve then directed the adsorbate I nitrogen mixture of known concentration $\left(C_{0}\right)$ into the sample chamber where adsorption occurred. The accompanying exothermic response was recorded as a function of time by the calorimeter thermistors. After times, which varied from several minutes to several hours depending on the experimental conditions, the thermal response returned to the baseline, signifying attainment of adsorption equilibrium. At this steady state, switching to the pure nitrogen stream allowed measurement of a desorption (endothermic) response. After desorption for a specified period, another adsorption response could be initiated by switching to the adsorbate / nitrogen stream again. Several successive adsorption/desorption cycles could be carried out. 
For each run, a thermal calibration pulse of known energy was produced by resistive heating in the sample cell allowing the measured adsorption I desorption responses to be expressed in energy units $(\mathrm{J} / \mathrm{g})$. All runs were conducted in triplicate each with a fresh carbon sample and the average integral heat of adsorption / desorption $(\mathrm{J} / \mathrm{g})$ given by FMC was calculated.

To determine the integral molar heats of adsorption and desorption of toluene on Maxsorb AW20, the concentration changes in the FMC effluent was achieved by directing the stream leaving the FMC cell to a downstream detector (DSD). The signal from the detector was monitored simultaneously with the heat of adsorption using the dual channel recording and data storage system incorporated in the FMC control unit. The toluene concentration downstream of the calorimeter was measured with a HNU DL-101 photoionization detector (PID). When the thermal response returned to the baseline in the adsorption half cycle, PID reached $\mathrm{C}_{\mathrm{o}}$. Switching to the pure nitrogen stream allowed measurement of endothermic desorption response along with the accompanying DSD measurement of desorbing molecules. Blank runs on non-adsorbing solid Teflon powder samples were used to determine the amount of adsorbate vapor adsorbed. Integrating the difference in apparent vapor concentration between the adsorption sample and the Teflon blank with respect to time at known flow rate and $\mathrm{C}_{\mathrm{o}}$ did this.

\section{Gravimetrical System}

Maxsorb AW20 equilibrium adsorption isotherm was conducted gravimetrically at $343 \mathrm{~K}$, same temperature of the carbon bed in the calorimeter sample chamber. The gravimetrical system consisted of Cahn Model D-200 Digital Recording Microbalance with a water flow jacketed isothermal flow tube, two Poly Science Digital Temperature Controller circulating water bath (one to control the temperature of the jacketed flow tube of the balance and the other to control the temperature of the toluene generator), and two MKS Model 1259C Mass Flow Controller. In this system, toluene vapor was generated practically in the same manner as in the FMC system. Dry nitrogen was split into a diluent (dry stream) and a vapor carrier stream (wet stream), each was maintained at a selected flow rate by the mass flow controller. The carrier stream passed through toluene liquid in the vapor generator, which was held at $15^{\circ} \mathrm{C}$ in a water bath. Nitrogen saturated with toluene and diluent nitrogen was combined into one stream before entering the jacketed isothermal flow tube. Mixing was done in the ratio required to achieve a vapor concentration corresponding to the desired adsorption vapor pressure calculated from the ideal gas law. The ratio between the dry stream and the wet stream was changed in steps such that the mixed stream had a constant flow rate. The mixed stream flowed past a carbon sample of a given weight in a small pan, which was suspended by platinum wire from the weighing arm of the balance in the jacketed flow tube. Digitized output from the microbalance was converted into weight vs time data in a PC equipped 
with Cahn proprietary software. When equilibrium between the carbon sanple and the following stream was attained, the balance showed constant reading. The increase in the sample weight as a function of the used relative pressure was recorded and the ratio between the dry and the wet streams was then changed. From the microbalance data and with the aid of spreadsheet software (QuattroPro), the equilibrium adsorption isotherm was calculated.

\section{RESULTS AND DISCUSSION}

The heat of adsorption or desorption during adsorption/desorption processes are displayed in graphical form by FMC. A typical FMC thermal response trace is shown in Fig.1. One adsorption response and one desorption response in pure nitrogen are shown in Fig.1 for toluene adsorption on Ambersorb 572 at $313 \mathrm{~K}$. As can be seen from Fig.1, the result for the heat of adsorption is a peak and in the adsorption half -cycle no further adsorption cccurred after the recorder trace returned to the base line. This occurred even with continuous flow of the carrier gas - adsordate stream through the sample bed and signifying the exhaustion of the carbon sample with the adsorbate under the used experimental conditions. When adsorption was completed and the recorded trace returned to the base line, switching to the pure nitrogen stream allowed measurement of a desorption (endothermic) response. The areas under the peaks in FMC trace represent the integral heat of adsorption or desorption (expressed in $\mathrm{J} / \mathrm{g}$ ) which depend on and related to the amount of adsorbate adsorbed or desorbed. Two lines designated the start time and the end time for computing a peak area. These lines were selected such that recorded trace was on the base line and the area under the peak was computed between these two lines. It was found that, desorption processes needed very long periods of time to be complete (in comparison with adsorption periods). Therefore, the end time for desorption peak was taken when the recorder trace almost returned to the base line

Figs. 2 and 3 represent the adsorption of trichloroethylene and carbon tetrachloride on Ambersorb 572 at $313 \mathrm{~K}$, respectively. Table 3 lists integrals heat of adsorption and desorption of the first cycle for the three adsorbates at the experimental conditions given in part A of Table2.

Table 3. Integrals heat of adsorption and desorption of toluene, carbon tetrachloride and trichloroethylene on Ambersorb 572 at $313 \mathrm{~K}$.

\begin{tabular}{|l|c|c|}
\hline \multirow{2}{*}{ Adsorbate } & \multicolumn{2}{|c|}{ Integral heat $(\mathrm{J} / \mathrm{g})$} \\
\cline { 2 - 3 } & $\Delta \mathrm{H}_{\text {Ads }}$ & $\Delta \mathrm{H}_{\text {Des }}$ \\
\hline Toluene & 488.4 & 61.7 \\
\hline trichloroethylene & 431.3 & 121.2 \\
\hline carbon tetrachloride & 265.9 & 117.6 \\
\hline
\end{tabular}


Table 3 shows that, the integral heat of desorption were smaller than that of adsorption for the three adsorbates used for desorption times employed in these runs.

The instrument was calibrated during each run, as mentioned above, by introducing a known quantity of heat as a thermal calibration pulse of known energy. No correction was applied for the heat of adsorption of nitrogen, which is estimated to be $<1 \mathrm{~J} / \mathrm{g}$ based on earlier calorimetric study of nitrogen adsorption from a helium stream on activated carbon at $295 \mathrm{~K}$ [15].

Figures 4-8 shows the FMC thermal response traces for runs done with the five microporous carbons stated in Table 1. Three adsorption responses at a toluene relative pressure of $6.35 \times 10^{-2}$ and three desorption responses in pure nitrogen are shown for toluene adsorption on these carbons at $343 \mathrm{~K}$ (two in case of Maxsorb AW30). Table 4 lists the heats of adsorption and desorption associated with these runs. The second and the third adsorption responses produced less heat than the first response, indicating the extent of toluene retention for the desorption time employed in these runs. The adsorption heats were always higher than the desorption heats even though, after the first adsorption response, the same amount of toluene was desorbed and adsorbed successively. The desorption profiles were obtained with a constant desorption time in each run. It is not clear what is causing this discrepancy.

Table 4. Integral heats of adsorption and desorption of toluene on microporous carbons.

\begin{tabular}{|c|c|c|c|c|c|c|}
\hline \multirow{2}{*}{ Carbon } & \multicolumn{6}{|c|}{ Integral heat (J/g) } \\
\cline { 2 - 7 } & \multicolumn{2}{|c|}{ First cycle } & \multicolumn{2}{|c|}{ Second cycle } & \multicolumn{2}{c|}{ Third cycle } \\
\cline { 2 - 7 } & $\Delta H_{\text {Ads }}$ & $\Delta H_{\text {Des }}$ & $\Delta H_{\text {Ads }}$ & $\Delta H_{\text {Des }}$ & $\Delta H_{\text {Ads }}$ & $\Delta H_{\text {Des }}$ \\
\hline Ambersorb 572 & 294.5 & 67.7 & 84.9 & 66.8 & 84.2 & 67.7 \\
\hline Ambersorb 563 & 166.7 & 26.8 & 62.5 & 25.3 & 61.6 & 25.5 \\
\hline WV-A1100 & 222.2 & 152.2 & 182.4 & 151.6 & 181.7 & 151.9 \\
\hline Maxsorb AW30 & 668.3 & 426.5 & 518.6 & 423.1 & & \\
\hline Maxsorb AW20 & 354.7 & 108.0 & 141.2 & 105.7 & 140.4 & 104.1 \\
\hline
\end{tabular}

Blank run on non-adsorbing solid Teflon powder sample is shown in Fig.9. The adsorption of toluene on Teflon produced negligible thermal response, Fig.9A. Toluene concentration downstream of the calorimeter, measured with the photoionization detector, is shown in Fig.9B. Almost instant breakthrough of toluene concentration occurred during the adsorption of toluene on Teflon. This response may be used to determine the amount of adsorbate vapor adsorbed on various adsorbents. Fig.10A shows the FMC thermal response 
trace and the corresponding DSD response trace, Fig.10B, for adsorption of toluene at a relative pressure of $6.35 \times 10^{-2}$ on Maxsorb AW20 at $343 \mathrm{~K}$. When the toluene/nitrogen mixture was directed into the sample chamber where adsorption occurred, the calorimeter recorded the accompanying exothermic response and the DSD recorded the toluene concentration downstream of the calorimeter. When the thermal response returned to the baseline, signifying attainment of adsorption equilibrium, the adsorbate concentration downstream reached the initial concentration $C_{0}$. At this steady state, switching to the pure nitrogen stream allowed a desorption (endothermic) response along with the accompanying DSD measurements of desorbing molecules. The change in the DSD reading due to adsorption or desorption are related to changes in [)SD readings produced when using Teflon as an adsorbent. Fig. 10B shows the DSD response for the adsorption of toluene on Maxsorb AW20 (shown in the reverse direction) after subtracting the DSD response from that of Teflon sample under the same exposure conditions. While the areas in the FMC trace Fig.10A represent the integral heat of adsorption or desorption (expressed in $\mathrm{J} / \mathrm{g}$ ), the areas in DSD trace Fig.10B represent the amount adsorbed or desorbed (expressed in micromoles per $\mathrm{g}$ ). The ratio of these quantities was used to obtain the integral molar heat of adsorption (expressed in $\mathrm{kJ} / \mathrm{mole}$ ). In this run, as shown in Fig.10, several successive adsorption/desorption cycles were carried out. Table 5 reveals the integral and the molar heats of adsorption and desorption of toluene on Maxsorb AW20 associated with the six adsorption/ desorption cycles in Fig.10. The six desorption profiles were obtained with a constant desorption time. The duration time for dsorption in each cycle was adjusted to equal that of adsorption (120 $\mathrm{min})$. The adsorption heats were always higher than the desorption heats, even though after the first adsorption response, the same amount of toluene is being desorbed and adsorbed successively. The average molar heat of adsorption from the 6 adsorption half- cycles is 97.6 $\mathrm{kJ} /$ mole and the average molar heat of desorption from the 6 desorption halfcycles is $47.2 \mathrm{~kJ} / \mathrm{mole}$.

Table 5. Integral and molar heats of adsorption and desorption of toluerie on Maxsorb AW20 at relative pressure 0.0635 and $343 \mathrm{~K}$.

\begin{tabular}{|c|c|c|c|c|c|c|}
\hline \multirow{2}{*}{$\begin{array}{c}\text { Cycl } \\
\mathrm{e}\end{array}$} & \multicolumn{2}{|c|}{$\begin{array}{c}\text { Integral heat } \\
(\mathrm{J} / \mathrm{g})\end{array}$} & \multicolumn{2}{c|}{$\begin{array}{c}\text { DSD amount } \\
\text { ( } \mu \text { mole/g) }\end{array}$} & \multicolumn{2}{c|}{$\begin{array}{c}\text { Molar heat } \\
\text { (kJ/mole) }\end{array}$} \\
\cline { 2 - 7 } & Adsor. & Desor. & Adsor. & Desor. & Adsor. & Desor. \\
\hline 1 & 354.0 & 108.5 & 3584.3 & 2367.6 & 98.8 & 45.8 \\
\hline 2 & 141.3 & 105.6 & 1446.6 & 2216.9 & 97.7 & 47.6 \\
\hline 3 & 140.4 & 104.1 & 1449.9 & 2196.0 & 97.2 & 47.4 \\
\hline 4 & 140.8 & 104.5 & 1449.2 & 2206.3 & 97.2 & 47.4 \\
\hline 5 & 140.7 & 103.9 & 1448.8 & 2178.4 & 97.1 & 47.7 \\
\hline 6 & 140.1 & 102.1 & 1436.5 & 2153.1 & 97.5 & 47.4 \\
\hline
\end{tabular}


A gravimetric adsorption isotherm of toluene on Maxsorb AW20 is shown in Fig.11. The relative pressure $P / P_{0}$ was calculated from the relation:

$P / P_{0}=\left(P_{1} / P_{2}\right) \times$ (flow rate of generator stream/flow rate of the mixed stream) Where $P_{1}$ and $P_{2}$ were toluene vapor pressures at the generator temperature $(288 \mathrm{~K})$ and the carbon bed temperature $(343 \mathrm{~K})$. From the adsorption isotherm, the amount of toluene adsorbed at a relative pressure 0.0635 in micromoles per gram units is 4019 . Combining the thermal data from the FMC and the isotherm data from the microbalance, the molar heat of adsorption (using the first cycle) is $88.1 \mathrm{~kJ} / \mathrm{mole}$ which is in a qualitative agreement with that obtained from FMC/DSD data $(97.6 \mathrm{~kJ} / \mathrm{mole})$.

\section{CONCLUSIONS}

The integral heats of adsorption of molecules from a gas flow stream can be rapidly determined by flow adsorption microcalorimetry. The technique can provide a wealth of information on the heat evolved and the adsorptive properties of activated carbon adsorbents. The molar heats determined from FMC/isotherm data are in qualitative agreement with molar heats obtained from FMC results and the adsorption amount determined with DSD.

\section{REFERENCES}

1- D.M. Ruthven, "Principles of adsorption and adsorption processes", John Wiley \& Sons, New York (1984).

2- $\quad$ E.A. Flood, "The solid - gas interface", V. 1, New York (1967).

3- M.Z. Hussein, R.S.H. Tarmizi, Z. Zainal, and R. Ibrahim, Carbon, 34, pp. 1447(1996).

4- $\quad$ M.Z. Hussein, Z. Zulkarnain, R. Ibrahim, K.K> Keong and B. Muhammad, J. Chem. Tech. Biotechnol. 64, pp. 35 (1995).

5- F. Caturla, M. Molina-Sabio and F. Rodriquez-Reinoso, Carbon, 29, pp. 999 (1991).

6- A.G. Pandolfo, M. Amini-Amoli and J.S. Killingley, Carbon, 32, pp. 1015, (1994).

7- $\quad$ S. Balci, T. Dogu and H. Yucel, J. Chem. Tech. Biotechnol. 60, pp. 419 (1994)

8- R. Arrigada, R. Garcia and P. Reyes, J. Chem. Tech. Biotechnol. 61, pp. 427 (1994). 
9- $\quad$ K. Gergova, N. Petrov and S. Eser, Carbon, 32, pp. 693 (1994).

10- Marsh, H. and Crawford, D. C., Carbon, 20, 419, 1982,

11- W'ennerberg, A. N. and O'Grady, T. M. US Patent 4,082,684, 1978.

12- A.J. Groszek, Proc. Roy. Soc., A314, pp. 473 (1970).

13- A.J. Groszek, carbon, 27, pp. 33 (1989).

14- G. Steinberg, Chemtech, 11, pp. 730 (1981).

15- J.F. Byrne, A.J. Groszek and H. Marsh, presented at the Carbon'88 Conference, Newcastle, United Kingdom, October 1988. 


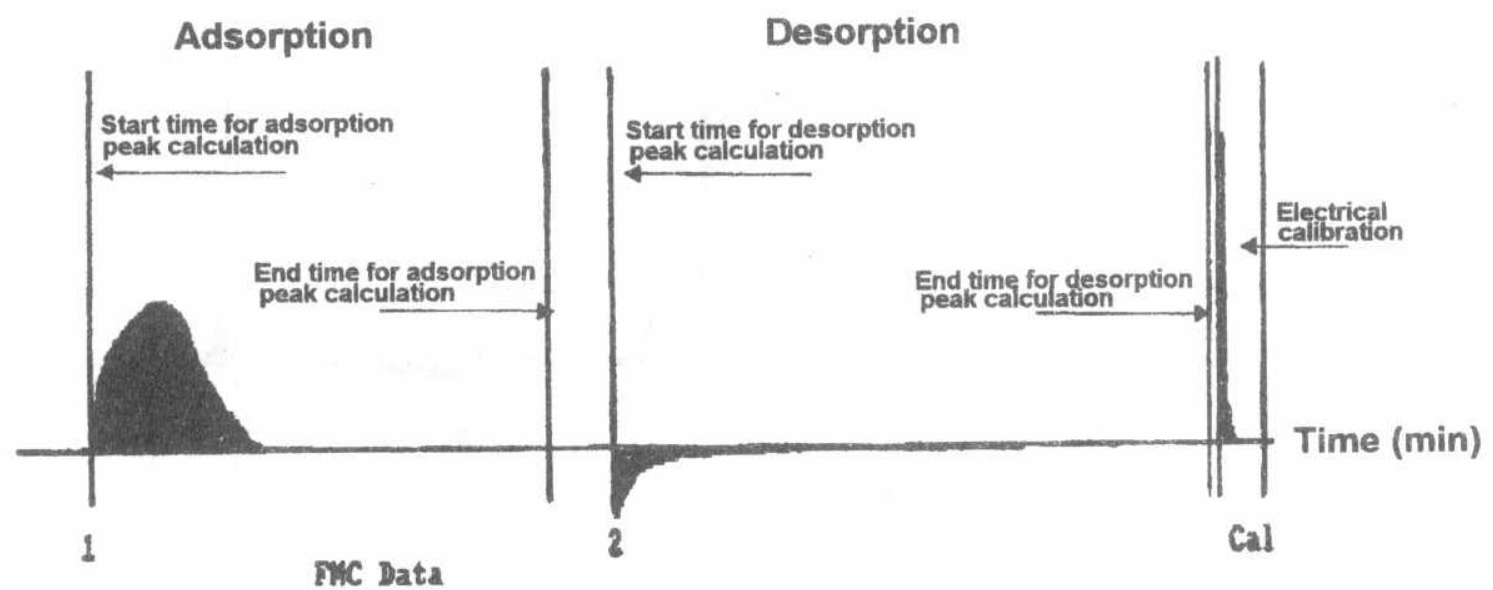

Fig.1 Heats of adsorption and desorption of toluene on Ambersorp 572 at $343 \mathrm{~K}$.

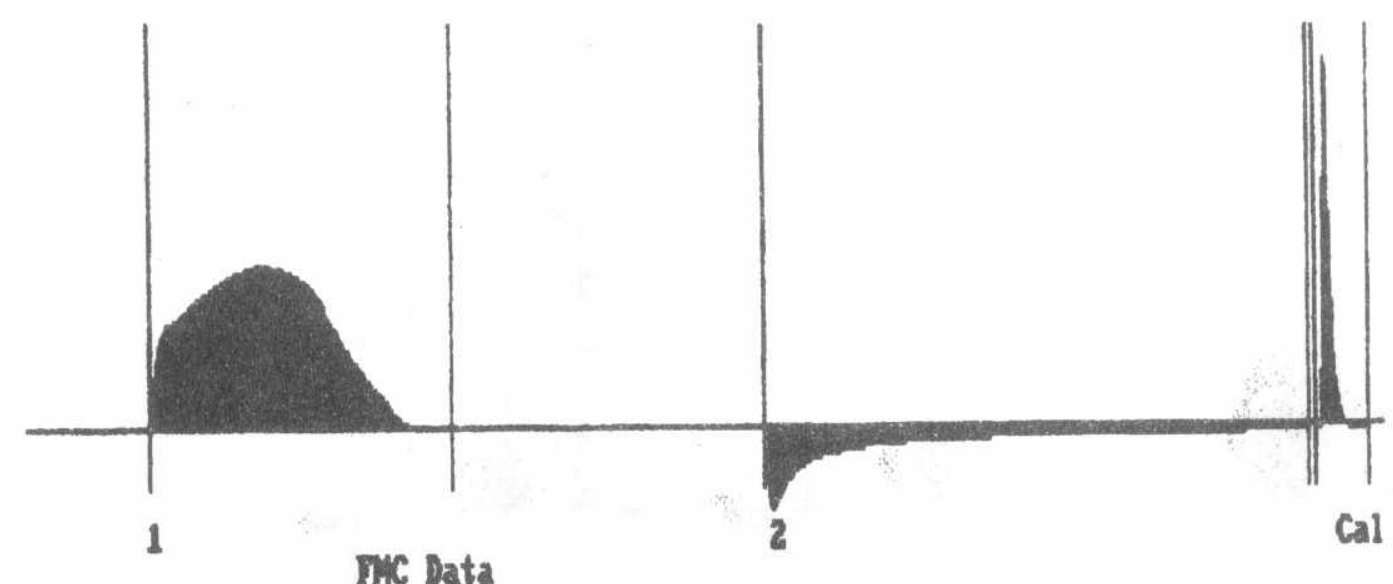

Fig.2 Heats of adsorption and desorption of trichloroethylene on Ambersorb 572 at $313 \mathrm{~K}$. 


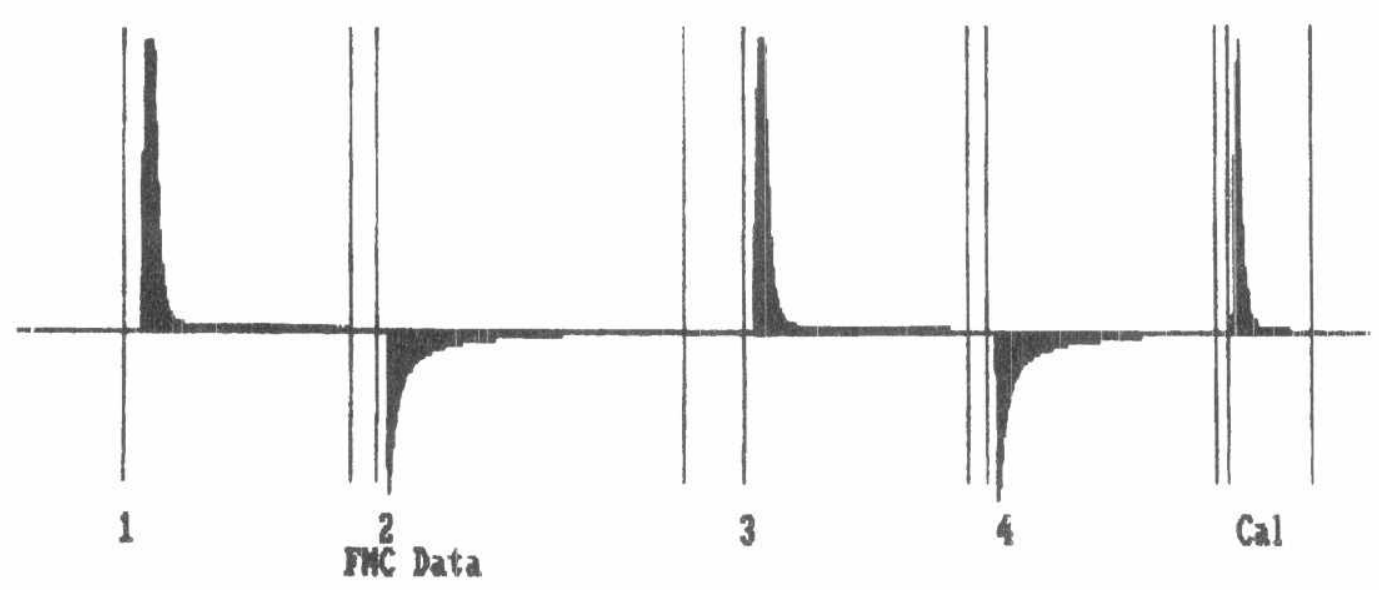

Fig. 3 Heats of adsorption and desorption of carbon tetrachloride on Ambersorb 572 at $313 \mathrm{~K}$.

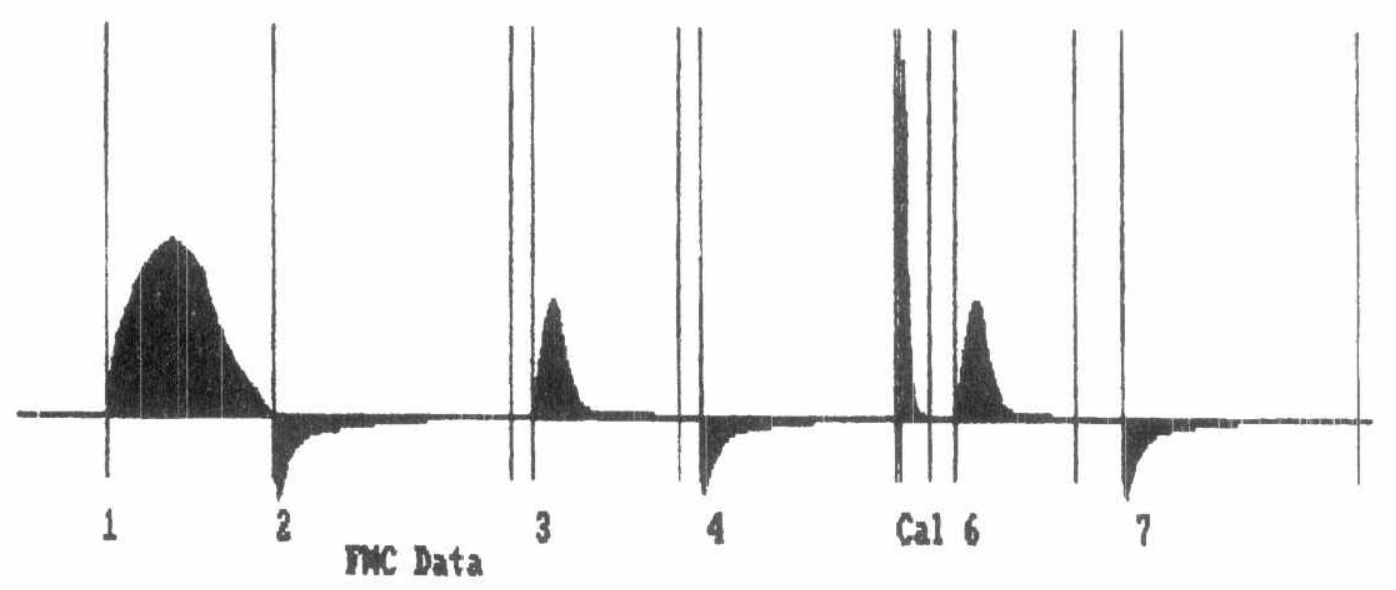

Fig.4 FMC thermal response during three adsorption / desorption cycless of toluene on Ambersorb 572 at $343 \mathrm{~K}$. 


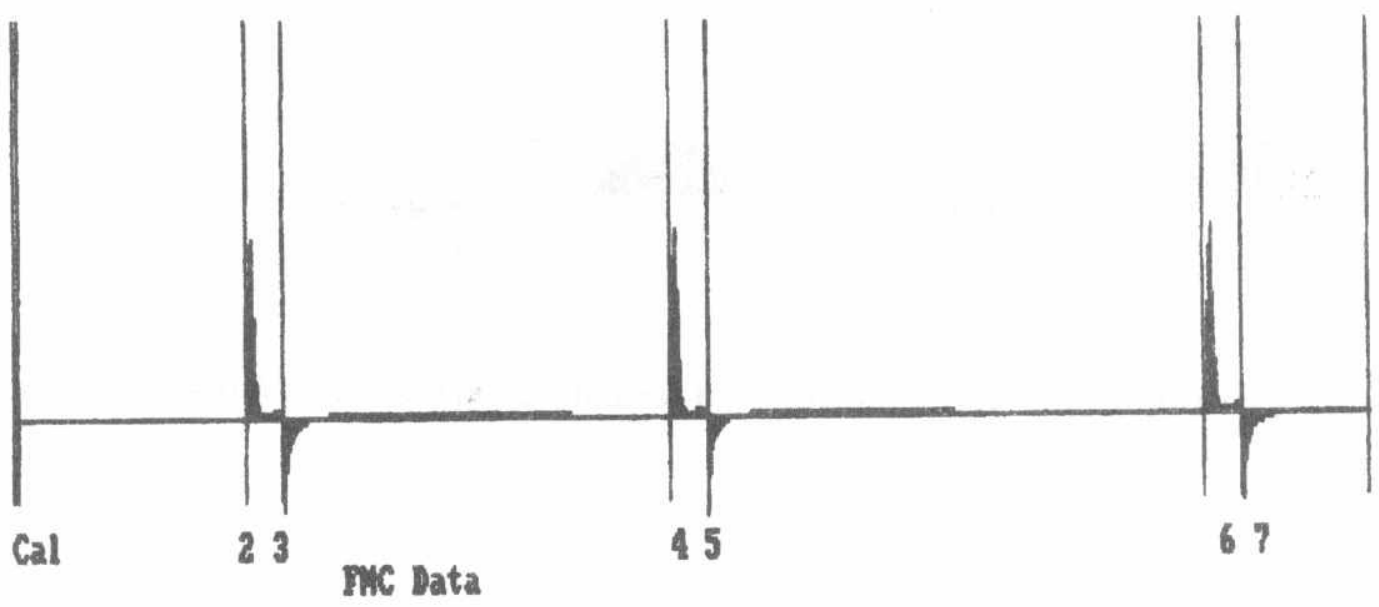

Fig.5 FMC thermal response during three adsorption / desorption cycles of toluene on Ambersorb 563 at $343 \mathrm{~K}$.

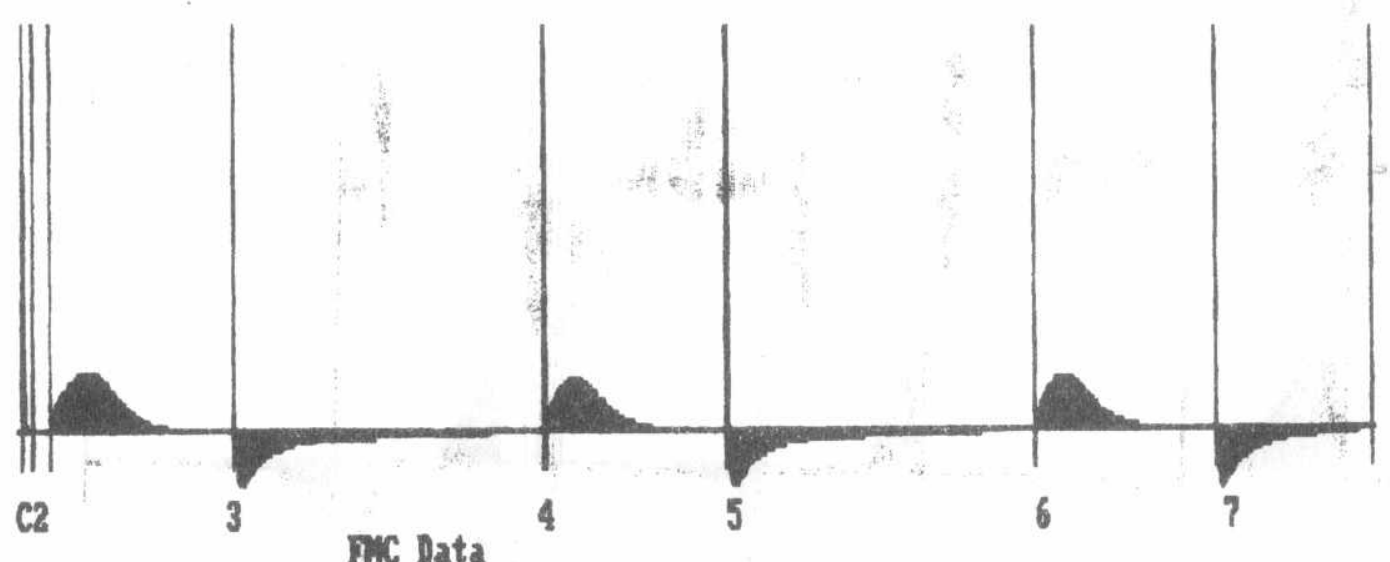

Fig.6 FMC thermal response during three adsorption / desorption cycles of toluene on WV-A1100 at $343 \mathrm{~K}$. 


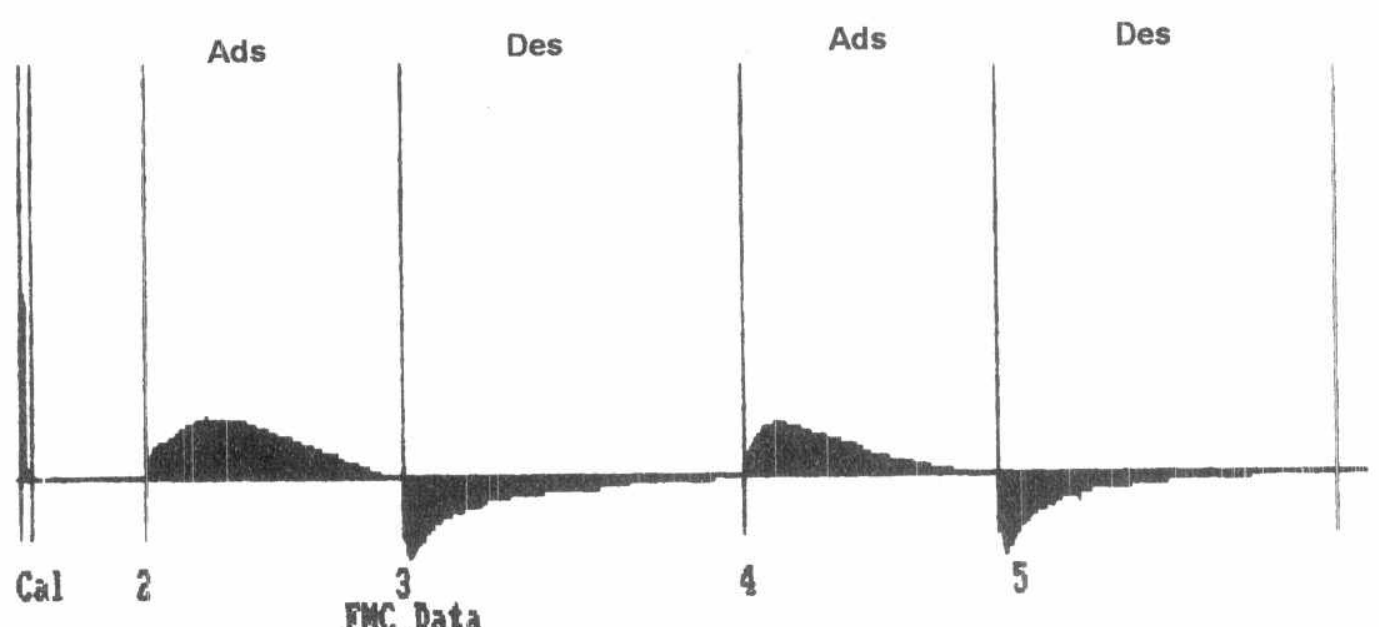

Fig.7 Heats of adsorption and desorption of toluene on Maxsorb AW30 at $343 \mathrm{~K}$.

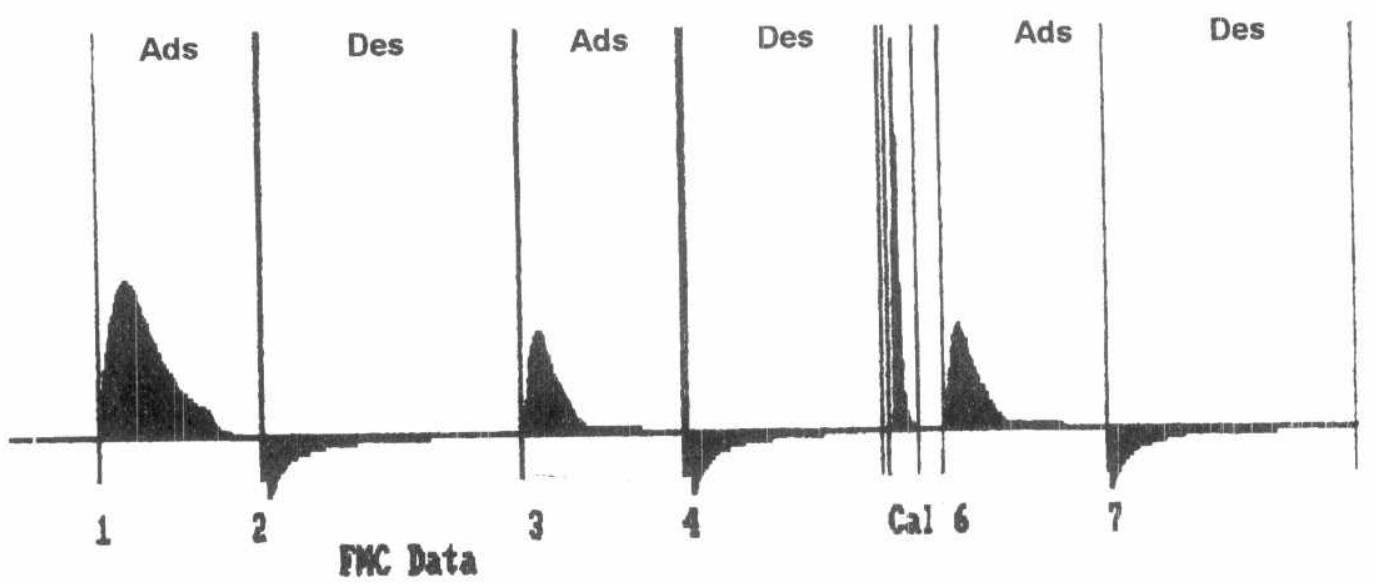

Fig.8 Heats of adsorption and desorption of toluene on Maxsorb AW20 at $3343 \mathrm{~K}$. 


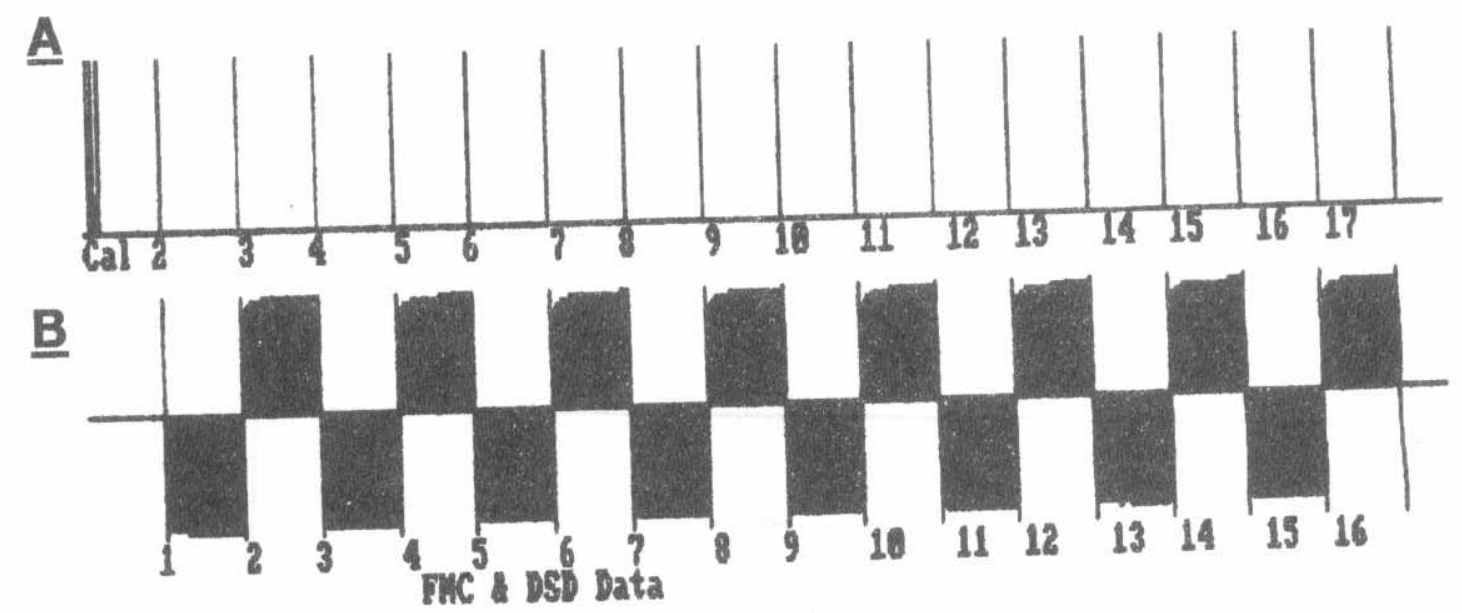

Fig.9 Adsorption / desorption of toluene on Teflon at $343 \mathrm{~K}$.

A- FMC thermal respose.

B- DSD response.

A
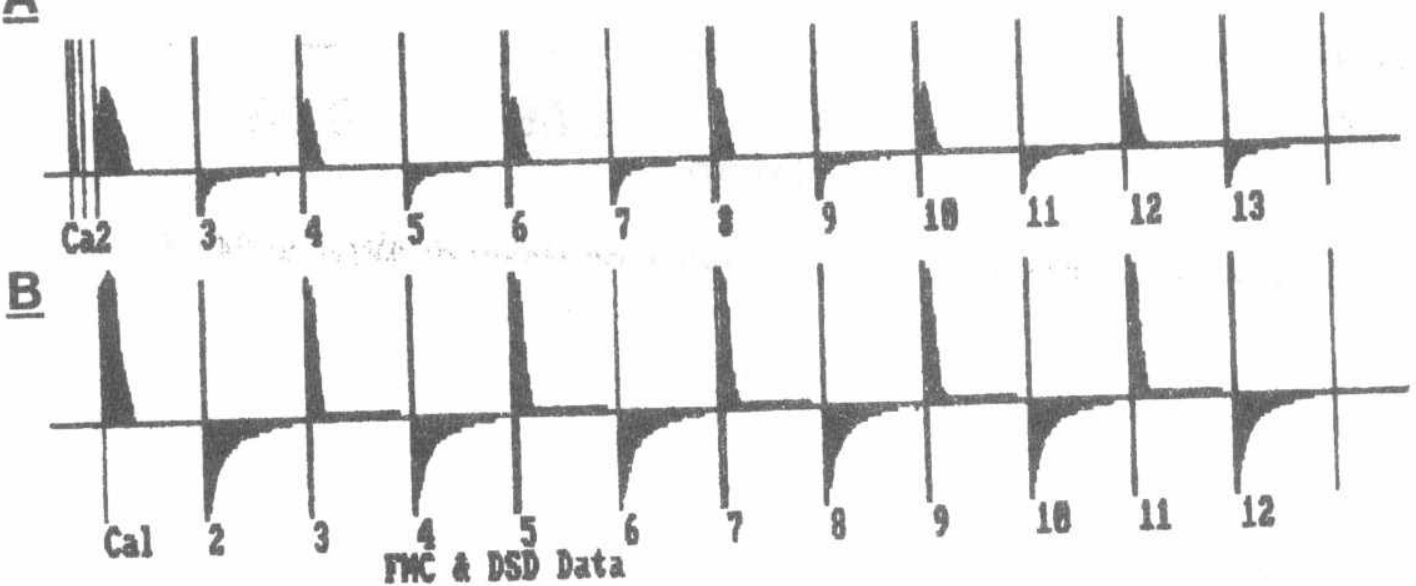

Fig.10 Adsorption / desorption of toluene on Maxsorb AW20 at $343 \mathrm{~K}$

A- FMC thermal response.

B- DSD output after sutracting the DSD response for Maxsorb AW20 from the DSD response for the Teflon. 


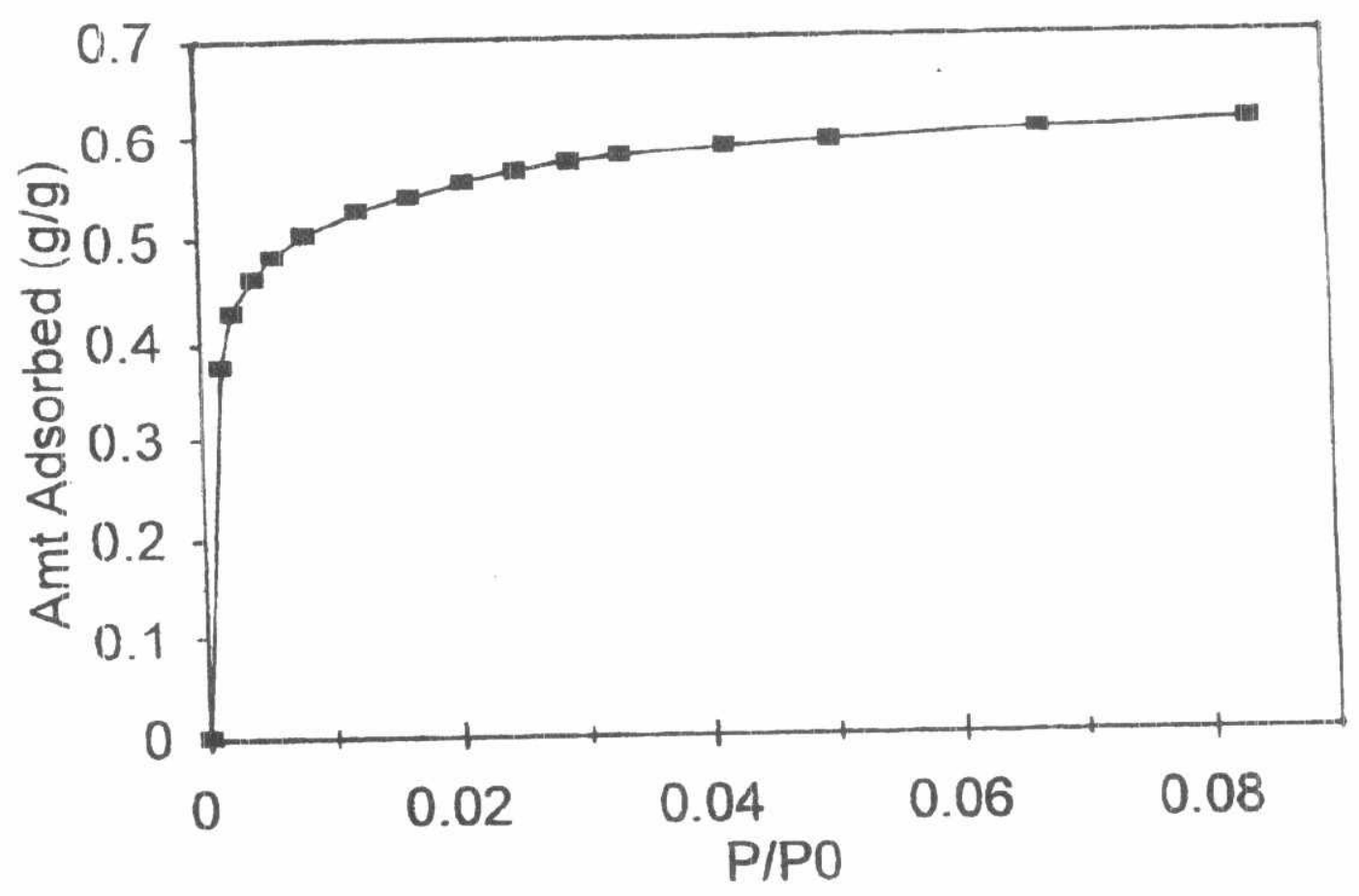

Fig.11 Adsorption isotherm of toluene on Maxsorb AW20 at $343 \mathrm{~K}$. 